\title{
Saberes compartidos
}

\section{entre generaciones:}

circulación de libros usados

en Nueva España durante

los siglos XVII y XVIII

\section{Knowledge Shared between Generations: Circulation \\ of Used Book in New Spain during I $7^{\text {th }}$ and I $8^{\text {th }}$ Century}

DOI: http://doi.org/10.22380/20274688.672

Recibido: 20 de septiembre del 2018

Aprobado: 22 de marzo del 2019
Universidad Nacional Autónoma de México, Ciudad de México

Escuela de Doctorado, Universidad Nacional de Educación a Distancia, Madrid, España

pulga@iibi.unam.mx

\section{R E S U M E N}

La historia de la circulación y venta de libros en Nueva España no es un tema nuevo de investigación, a pesar de lo cual los estudios dedicados a libreros, mercaderes de libros y al conjunto de libros que ofertaron a la sociedad colonial son escasos. Estas personas consolidaron un mercado libresco alimentado por redes comerciales y familiares de quienes se movían en la Carrera de Indias. El estudio y comparación de nuevas evidencias, bibliográficas y documentales, contrastadas con investigaciones previas, permiten advertir una constante circulación de libros usados en dicho mercado. Se trata de testimonios que necesariamente modifican nuestra apreciación de una cultura letrada solo asequible para quienes podían pagar una mercancía considerada costosa.

Palabras clave: circulación de libros, Nueva España, libreros, Inquisición, mercado de libros, libros usados.

Doctora en Documentación Científica de la Universidad de Granada. En la actualidad estudia el Doctorado en Historia e Historia del Arte y Territorio en la Escuela de Doctorado de la UNED (Universidad Nacional de Educación a Distancia). Investigadora del Instituto de Investigaciones Bibliotecológicas y de la Información de la Universidad Nacional Autónoma de México (UNAM) y miembro del Sistema Nacional de Investigadores (Conacyt). https://orcid.org/0000-0003-1729-4810 


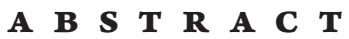

Commerce and Circulation of books in New Spain is not a new research topic. However, studies focused on booksellers, merchants and the offers they would give on books to the colonial socieare limited. They consolidated a market, fed by commercial and family networks, who participated in the Carrera de Indias. The study and comparison of new testimonies, both bibliographic and documental, with preliminary researches, allows to understand a constant traffic of second hand books. These evidences nemodify our appraisal on a learned culture, thought to be only accessible for those who could pay a costly merchandise.

Keywords: book's circulation, New Spain, booksellers, Inquisition, book market, used books.

Un fondo de librería consiste en un número más o menos considerable de libros apropiados para los diferentes estamentos de la sociedad, y surtido de tal manera que la venta más lenta de unos se compense con la venta rápida de otros, favoreciendo el incremento de la primera posesión. Cuando no se ciñe a estas condiciones, un fondo resulta ruinoso.

Denis Diderot ( 1763$)$

\section{Introducción}

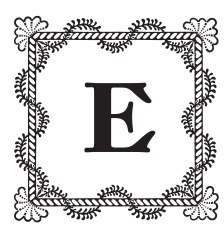

122 de abril de 1564 se inició el proceso contra Alonso de Castilla por "su costumbre de comprar y vender libros prohibidos en el catálogo". La denuncia fue presentada por el dominico fray Bartolomé de Ledesma ante el arzobispo de México, Alonso de Montúfar. Esta es la primera noticia que tenemos sobre mercaderes de libros en Nueva Espańa. Los protagonistas de este evento fueron, uno, el procesado, dos, Alonso de Ballesteros, quien le vendió los libros, y el tercero, Alonso de Losa, testigo de la parte acusadora. El proceso completo fue dado a conocer por la transcripción que Fernández del Castillo publicó en I9I4 (48-80) y también mostró las formas en que este librero vendía algunos libros entre dedales, espejos y peines. 
A partir de ese momento se han dado a conocer numerosas noticias sobre el mercado del libro durante el periodo colonial en diferentes trabajos, entre los que se destacan los de Leonard, O'Gorman, Torre, Rojo y Rueda (Negocio). Empero, los estudios hasta ahora realizados se han centrado en algunos libreros activos en la capital del virreinato, con contadas excepciones, como el caso de Puebla en el siglo XVII (Rueda, "Libreros"), Nueva Galicia hasta el siglo XVIII (Castañeda, "Libros en") y Guadalajara a principios del siglo xıx (Castañeda, "Libros como"). Por otro lado, las investigaciones solo se han interesado en aquellas personas que tenían un establecimiento o tienda de libros y no en otros mercaderes que también vendían libros, pero no de forma especializada.

Pese a estos esfuerzos, tampoco se ha completado una nómina de todos los personajes que gobernaron los vericuetos de la circulación de libros en este territorio americano durante más de doscientos años. Un conjunto al que seguimos agregando nombres con alguna frecuencia cada vez que encontramos un nuevo librero o mercader del que no se tenía noticia o había pasado desapercibido. De los nombres de libreros conocidos se han elaborado dos relaciones generales que son la base de numerosos estudios (Moreno, "Hacia”; Zahar), empero, no hemos acabado de delinear las complejas redes comerciales que hicieron posible la circulación de libros en ciudades y pueblos novohispanos. En efecto, no solo tenemos que dilucidar entre los nombres conocidos quién pertenece a cierta red de abastecimiento, sino también el rol que desempeñaba en esa estructura, es decir, comprender con la mayor certeza posible las diferencias que existen entre aquellos que se reconocían como libreros, mercaderes de libros o tratantes de libros y quienes fungieron como factores ${ }^{\mathrm{I}}$, e incluso los dueños de recuas.

En este complejo universo de mercancías y personas siempre se ha supuesto que se movían libros nuevos y siempre a precios solamente accesibles para personas con recursos económicos. No obstante, nuevos testimonios históricos obligan a repensar en los documentos que ya se habían identificado. Estas novedades muestran cierta información que abre la posibilidad de que también se vendiesen libros usados. ¿Cómo definir a este tipo de objeto? Es una tarea compleja porque no contamos con una definición clara. Por tanto, podemos decir que básicamente se trata de cualquier libro que haya sido usado por una persona y

I Los factores eran intermediarios en las rutas comerciales del libro. Actuaban en nombre de otros para entregar y comprar mercancías, así como para recibir y hacer pagos. Por esa razón, como factores de mercaderes, podían viajar a Indias por tres años con la entrega de una fianza y compromiso de regresar (Recopilación 4, lib. 9, tít. 26, Ley 32 de diciembre de 1554, f. 6 r.) 
que posteriormente pasa a ser de otra. ¿Cómo determinamos este traspaso del objeto en el pasado novohispano? Tal problemática de investigación tiene una respuesta fácil si en un libro encontramos este tipo de evidencia, que suele ser manuscrita y de la cual tenemos bastantes ejemplos. En el espacio documental, solo en casos puntuales podemos determinar con certeza que un libro es usado. Los testimonios demuestran la circulación de saberes librescos pero no que esos libros se hayan vendido. Esto es sobre lo que nos interesa reflexionar aquí: las evidencias históricas que ayuden a comprender una posible venta de libros usados en la Nueva España.

\section{Los agentes comerciales del libro}

A la fecha sabemos con bastante certeza que algunos de estos personajes estaban relacionados de diferentes maneras con redes comerciales y productivas del libro en Europa. Es el caso, por ejemplo, de Simón de Toro, el hijo de Antonio de Toro, quien "fue uno más de los numerosos hombres de comercio que se convirtieron en una pieza clave del entramado que permitía el envío de libros a América" (Rueda, "Los libreros" 47). Sabemos también que otros participaban en la periferia de este comercio, como Felipe Pérez del Campo, quien vendía sus libros de persona a persona sin mediación y dejando el libro para la valoración del posible comprador (García y Montiel IO4). En cierta manera, esos personajes que actuaban al margen de una red fueron aventureros de una actividad complicada, riesgosa y estrechamente vigilada por el Tribunal del Santo Oficio.

Ahora bien, el conocimiento sobre este negocio y sus protagonistas se ha basado primordialmente en los registros de navíos que se han conservado en el Archivo General de Indias (España) y en los restos de información inquisitorial conservada tanto en archivos americanos como en uno que otro retazo que ha llegado a formar parte de una biblioteca contemporánea. Ambos rastros documentales son el resultado de una legislación específica que obligó a registrar los libros en circulación como mercancías ante la Corona española, y ante la Inquisición, como objetos culturales. Se trata de procedimientos bien descritos por otros (González y Rueda 474-480), que a través de un conocimiento puntual de los testimonios documentan cómo los libros eran revisados en el puerto de salida y en el de llegada.

Afortunadamente, se han conservado suficientes testimonios para conocer qué obras circularon más entre el siglo XVI y principios del XIX, mientras los 
territorios americanos estaban bajo el gobierno de la Corona española. Ciertamente, la conservación de la documentación colonial no ha sido igual para todos los virreinatos americanos. Se trata de historias complejas que involucran instituciones nacionales fundadas entre el siglo xIx y el xx, y que tienen diferentes valoraciones sobre ese legado bibliográfico y documental. Dicha valoración patrimonial ha sido determinante para garantizar la conservación de estos testimonios, tanto como para posibilitar su destrucción, especialmente aquella documentación que fue producida por los inquisidores en Nueva España, Perú y Nueva Granada, como sedes de los tribunales territoriales de América. No olvidemos que el libro en circulación fue casi competencia exclusiva del Santo Oficio y que su preocupación por controlar estos objetos tiene que ver con impedir la dispersión de la herejía y así mantener la ortodoxia religiosa.

En este tenor, el entramado institucional y normativo de la Inquisición, así como las complejas razones ideológicas y teológicas (Vega 27), delinearon la censura de libros durante la Edad Moderna. Esta temática, que corresponde al debate de la represión inquisitorial de los libros y las ideas, fue introducida en España hace ya más de treinta años por dos trabajos que siguen siendo fundamentales (Pinto; Tomás). En América, la temática inquisitorial comenzó desde I905 con el caso mexicano (Medina) y ha corrido por interesantes derroteros que sin duda requieren su propio estudio para cada territorio americano. Esto es necesario, precisamente, por los diferentes resultados obtenidos y las valoraciones sobre la actividad inquisitorial; empero, en este complejo panorama de textos y documentos, se han privilegiado tanto el estudio como las apreciaciones basadas especialmente en los índices inquisitoriales de los siglos XVI y XVII: "Valdés, I559; Quiroga, I583; Sandoval, I612-I4; Zapata, I628-32; Sotomayor, I640 y I667” (R. García 243).

Por su parte, en materia de comercio se ha prestado poca atención a la instrucción inquisitorial publicada por primera vez en I6I2 y titulada "Mandato a los libreros, corredores i tratantes de libros” (Index), que además se agregó a las posteriores ediciones del Index librorum prohibitorum. Este mandato reviste interés para el objeto de estudio que aquí analizamos, el libro usado como medio para la transmisión de saberes, porque obligó a los libreros a entregar una "memoria o inventario" de todos los libros que tuviesen en venta cada ańo. Como resultado del cumplimiento de esta normativa, se elaboraron listas de libros que fueron presentadas ante los inquisidores. El mandato fue de aplicación general, para todos los territorios bajo la jurisdicción de la Inquisición 
española, y Schons ha destacado que dicha normativa solo formalizó una tarea que se practicaba desde 1605 en el territorio novohispano (Book 2).

En México conservamos testimonios de dicha práctica elaborados en I585. Todos los documentos similares localizados hasta ahora de los siglos XVII y XVIII aportan datos tanto sobre las obras en circulación como de ciertos agentes comerciales del libro. La localización y transcripción de una parte de dichas fuentes, elaboradas durante el siglo XviI, se dio a conocer en 1939 (O'Gorman), pero no se mencionó nada sobre el procedimiento ni la normativa de la que son resultado. En consecuencia, las fuentes han sido juzgadas duramente por la información que contienen, pues se afirma que no es suficiente para identificar obras en circulación, ya que fueron elaboradas por personas con nula cultura intelectual (Hampe 30) y en un proceso desaseado, al igual que otros testimonios de librerías (Moreno, La librería IoI). Por el contrario, justamente en ese mandato citado de 1612, los inquisidores demandaron de manera específica que las listas de libros se hicieran en principio por abecedario, con nombres y sobrenombres de los autores. Un año después agregaron títulos, ciudades de impresión, años y licencias (AGNM, E, exp. I).

Esta petición fue constante y tiene que ver con el orden y el control de la información para poder identificar libros que eran una preocupación constante, derivada de otra práctica común que los inquisidores han identificado. De ahí la reiteración de la instrucción. Los libros sin control podían circular entre lectores y pusieron en riesgo la tarea de vigilancia inquisitorial y sus nobles finalidades. Por ello, los inquisidores nuevamente declararon en 1740 que:

[...] siendo asunto de la primera atencion de este Tribunal el evitar que en estos Reynos se introduzca el pestífero daño de la Heregia, y Libertinage, que por nuestros pecados vemos tan extendido; y reconociendo, que en estos Catholicos Dominios por la bondad de Dios, y celo de nuestro Catholico Soberano, con dificultad pueden los enemigos de la Iglesia propagar sus falsos dogmas sin valerse de los libros que han procurado esparcir aun en esta Ciudad de nuestra residencia, poniendolos en las listas que se nos presentan con nombres disfrazados y usando otros medios que sugiere la malicia para eludir nuestras cuidadosas providencias. (AGNM, IV, caja 30, f. I r.)

Esta preocupación da cuenta de cómo algunos libreros e impresores quizá ocultaban información en sus registros, intentado con ello evitar sospechas sobre su mercancía. También, agentes comerciales e inquisidores sabían que no 
todas las obras de un autor estaban prohibidas, pero algunas generaban cierta suspicacia. Ciertos libreros novohispanos no aportaron con precisión los datos solicitados en sus memorias y desconocemos las razones, aunque otro grupo, nada despreciable, sí lo hizo. Estos son los testimonios que nos interesan porque, además de informar sobre ediciones puntuales en circulación, aportan datos bastante precisos que permiten pensar en el comercio de segunda mano del libro durante el periodo novohispano. Se trata de libreros de quienes, en algunos casos afortunados, conservamos memorias de diferentes años, como Agustín de Santiesteban y su contraparte, Francisco Lupercio o Paula de Benavides en el siglo Xvir, y Antonio Espinosa de los Monteros o Juan Bautista de los Reyes Chávez en el siglo XviII.

A este afortunado universo documental que da cuenta de la actividad profesional y la oferta de los libreros novohispanos, debemos sumar las memorias de bibliotecas particulares e institucionales que se conservan del periodo colonial. En estas también encontramos la presencia de libros que suponemos eran usados y que en conjunto constituyen una radiografía muy sugestiva del mundo del libro en Nueva España, la cual ofrece innumerables vetas de conocimiento que pueden explorarse. Como es evidente, se trata de una información cuyo análisis es bastante complejo y laborioso. Además, pese a que tenemos datos suficientes para identificar con precisión ediciones antiguas y todavía conservadas en repositorios contemporáneos, también contamos con un conjunto de datos que no logramos identificar, pues hemos perdido los códigos culturales necesarios para esta tarea. Por las características de los registros, parece que entre libreros, impresores, lectores e inquisidores se entendían y conocían esos códigos. Podemos afirmar lo anterior porque existe información compartida entre agentes sobre autores y obras, como el registro Cronicon de Adriconio, que con ligeras variantes veremos presente en diferentes memorias de libreros y lectores en catálogos impresos de libros en venta durante la época colonial.

Tristemente, una parte importante de esos impresos y manuscritos que conformaron el universo intelectual de la Edad Moderna hispánica se ha perdido para siempre, por numerosas razones históricas. Aquellos libros perdidos también constituyen una línea de investigación que ha comenzado a tener partidarios, gracias a que ahora contamos con instrumentos electrónicos que han compilado una gran parte de esa producción, ya sea porque se conserva o porque quedó registrada en documentos o catálogos del pasado (Wilkinson 4). Empero, entre nuestros pendientes han quedado esos libros transmitidos entre generaciones que estuvieron circulando durante todo el periodo colonial. Libros 
que fueron comunes, mucho antes de convertirse en las delicias de los bibliófilos decimonónicos y contemporáneos.

\section{Los viejos siguen circulando}

La preocupación o interés por el comercio del libro usado surgió gracias a una investigación recientemente terminada, que estuvo dedicada a las bibliotecas privadas de la Nueva España durante los siglos XVıI y XVıII. Nuestra intención siempre fue localizar documentación inédita, para contribuir a ese universo documental de la cultura del libro novohispano. Los estudios previos en esta temática han mostrado que las evidencias de esas colecciones, elaboradas en el siglo XVII, son bastante escasas. En consecuencia, en la investigación, y como se esperaba, obtuvimos más noticias del siglo xviII. Los testimonios localizados mostraron un proceso inquisitorial que desde 1632 controlaba la venta de bibliotecas de los difuntos, proceso que hemos estudiado escasamente. En nuestro primer acercamiento, el estudio ha dado por resultado la identificación de 3.IOI ediciones diferentes en circulación, de 3.55I registradas. La sorpresa fue testimoniar que una parte importante de estas obras registradas eran antiguas y no exclusivamente contemporáneas a la documentación. Es decir, $49 \%$ de esas ediciones fueron impresas entre los siglos XV y XVII (I. García, La vida), aunque hasta ahora solo hemos trabajado poco más del io \% de todas las bibliotecas localizadas (13 de I23). Sin embargo, en la actualidad se han sumado otros a la tarea de identificar ediciones en esta misma documentación y estamos apreciando la misma tendencia.

La misma investigación of reció datos nuevos que no habíamos considerado sobre libros usados por otros, de los que encontramos la primera evidencia documental entre los libros que tenía Gabriel de Cugar. En su testimonio se puede leer lo siguiente:

Otro libro llamado monte Calbario compuesto por el Reverendisimo señor don antonio de gevara obispo de mondonedo predicador coronista del consejo de su magestad nuevamente corregido y emendado por el Reverendo padre fray Alonso de Orosco y lo que con el se contiene se allara a la buelta de esta oja del uso de fray Jhoan Rodrigez con licencia en Salamanca en casa de pedro laso. Ano de 1582 espreso por diego del pino y Jhoan delgado (agnM, $I V$, caja 4217, f. 26 r. Énfasis añadido.) 
La parte del texto que distinguimos en cursiva se relaciona directamente con otro dato de interés para estudiar este comercio. Se trata de información obtenida en diferentes testimonios bibliográficos de procedencia virreinal que ayudan a comprender el origen de las colecciones de libros en México. Nos referimos a anotaciones manuscritas presentes en varios impresos, que indican "el uso" de un propietario del pasado. Notas semejantes a esta: "Del uso del Padre Fray Diego de Jesus Maria”. La nota de Cugar que hemos transcrito evidencia que su libro había pertenecido con anterioridad a fray Juan Rodríguez. Tal evidencia generó preguntas sobre esta posibilidad: dónde, cuándo y cómo Cugar había comprado el libro de ese fraile.

Las memorias que los libreros presentaron a la Inquisición desde principios del siglo XVII, incluso aquellas transcritas por O'Gorman, contienen cierta información que podemos entender como indicativa de libros usados. Nos referimos a los adjetivos calificativos "viejo", "roto" o "trunco" que denotan un contraste entre lo nuevo y lo viejo, además de la noticia de ciertos libros expurgados. Por ejemplo, en la memoria que entregó Alonso Bautista Montejano en I609 se anotó "que por faltarle algunas hojas del principio no se sabe por quien es compuesto ni a donde se imprimio" (AGNM, $I V$, caja 58II, ff. IV.); y en la que entregaron los libreros Agustín de Santiesteban y Francisco Lupercio en 1655 se consignó que el libro de Bartolomeo Fumo³ estaba "corregido por mandado de los señores inquisidores, conforme al Expurgatorio de I6I2, por el Padre Hortigosa” (O‘Gorman 724). Esta última nota da cuenta de que ese libro estuvo en algún lugar donde fue expurgado por este jesuita antes de ingresar a la oferta comercial de estos libreros.

En nuestra opinión, tales evidencias permiten diferentes análisis, pues en ellas existen valoraciones sobre los libros que fueron incluidas en el momento del registro, tales como "roído", "maltratado", "apolillado" o "bien tratado". Términos que sin duda dan cuenta del estado en que se encontraban los textos cuando fueron registrados. Para abonar a este argumento podemos ver algunas noticias de obras usadas que se comparten en otras memorias de libros de la época. Todas fueron elaboradas por los poseedores a petición de los inquisidores

2 Anotación manuscrita en guarda anterior del libro de Antonio de San José (O. C. D.) (1716-1794), Compendium Salmanticense in duos tomos distributum universae theologiae moralis quaestiones brevi... (Pompelonae: apud viduam Joseph Longás, 1797). Biblioteca Eusebio Francisco Kino 24588. Bartolomeo Fumo, Summa aurea armilla nuncupata, Venetiis: ex officina haeredum Melchioris Sessae, I572, IT \ICCU \RMLE\O02647. 
(I. García, "El movimiento" 66-69). Veamos un ejemplo de r603: "un librito de las excelencias de los gloriosos San Juan Bautista y San Juan Ebangelista faltale el prensipio y asi no se save el autor" (AGNM, JS, III-26, exp. 2, f. I v.). Uno de I6I2: "Un libro en latin yntitulado gesta romarum cum explanationibus moralisatis ac misticas, sin autor, ni dise el año de su ympresion es muy antiguo" (AGNM, $I V$, caja 42I7, f. 56 v.). Y uno más, de I6ı6: "otro libro intitulado la Reyna Saba que no tiene prensipio ni fin” (AGNM, JS, III-26, exp. 27, f. I v.).

Esta forma de valoración de lo incompleto, antiguo o maltratado parece compartirse también con las memorias elaboradas por las propias autoridades inquisitoriales, como esta de I655: "No esta entero ni tiene año de impresion" (AGNM, I, 440, f. 98 r.), y que se mantendrá en el siglo siguiente: “ya es viejo", para una obra de Juan Yáñez Parladorio, impresa en I604 (AGNM, I, IIoo, f. 2I4 r.); "trunco", para la obra Coordinatus de Antonino Diana, impresa en I667 (AGNM, I, 986, f. I59 v.); unas concordancias de la Biblia "mal tratadas" (AGNM, $I V, 4965$, f. I v.) y un breviario de un cuerpo "mui viejo" (AGNM, I, I333, f. 347 v.). En ciertos casos, muy puntuales, los testimonios dan cuenta del efecto en un libro que ha dejado su uso de cien años:

32 Buena (Doctor Maison). Piratas de la America, y Luz a la defensa de las costas de Yndias occidentales Ympreso en Colonia Agripina, en casa de Lorenso Struickman Año de 1687. este es un quaderno en quarto sin forro mui mal Tratado, roto.......................oor. (AHN, JS, leg. 9I, f. 3 r.)

Estos son tan solo unos cuantos ejemplos de cómo se registraron los que suponemos eran libros usados, por el deterioro que presentaban. Así, una expresión como "sin principio" puede entenderse como la ausencia del primer cuaderno que, según la legislación de la época, contiene la portada y los documentos preliminares. Otras descripciones, como "I Fortunato de veritate año de I594 sin caratula” (AGNM, I I296, f. 364 v.), podrían solo referirse a la ausencia de la portada, pues quien registró este libro no tuvo problema en identificar la fecha. Por su parte, las diferentes formas de manifestar lo "viejo" necesariamente se contraponen con la idea de que un libro es nuevo. Por ejemplo, "Quadernos de oficios nuevos de diversas impresiones, los mas de Mexico" (AGNM, I, I2I7, f. 193 r.), frente a "I tomo. folio Molina (Reverendo Padre Luis) De Justitia, et Jure; en Moguncia año de I6I4. Mui picado, viejo, y trunco: en pergamino" (AGNM, I I4OI, f. 376 r.).

Lo cierto es que estas precisiones se observan más en aquellas memorias de libros que contienen mucha información sobre una edición, mientras que 
en las otras, que registran solo autores y títulos, podemos encontrar apenas algunas consideraciones sobre el estado de los libros, cuando se consideraban necesarias. Al parecer, un libro "nuevo" se podría adquirir en cualquier librería o cajón de libros, tanto como uno viejo. Entonces, ¿cuáles serían el sentido y la finalidad de apuntar estas valoraciones? Es muy posible que esta información estuviera vinculada con la valuación económica de un libro que no podría dejar de conocer el comprador. Un precio por el que se ha considerado que los libros eran necesariamente una mercancía con precios altos. Sin embargo, la presencia de libros usados en casi todas las esferas de la circulación novohispana abre la posibilidad de que sus costos inevitablemente cambiasen las dinámicas comerciales. ¿Sería posible demostrarlo? Como hemos visto, por ahora no, porque necesitaríamos los precios de venta de los libros nuevos para compararlos con aquellos que pudiésemos probar que eran usados.

Evidentemente, es necesario cuestionar si este comercio habría sido del interés de los inquisidores y si lo controlaban con mayor atención. La evidencia hasta ahora compilada indica que los controles inquisitoriales diseñados para la circulación de libros no hacían tal distinción. Por el contrario, todos los que vendían libros en cualquier condición debían informar al Santo Oficio qué obras estaban vendiendo, cuando menos una vez al año. Ahora bien, también se ha mencionado que la venta de las bibliotecas privadas abastecía a las librerías de libros usados (Palmiste 60o). Se trataba de una especie de reciclaje de la literatura disponible en el territorio (González y Gutiérrez IO6), del cual no se han precisado detalles porque hemos tenido poco interés en estudiar a los libreros y sus redes comerciales. Por tanto, no sabemos si existía o no un mercado especializado.

En las almonedas, donde se vendían bienes de difuntos, habría ciertos libros que quizá abarataran el costo de la misma obra en el mercado regular (Gómez I3). Es posible que algunos libreros se abasteciesen en estas ventas de cierta mercancía para la que conocían compradores interesados (Moreno, "Hacia" I45), o que estos acudiesen a esas mismas almonedas para hacerse de libros pertenecientes a la colección de algún colega de profesión (Palmiste 60o). Lo que no podemos determinar es la proporción de "usado" y "reciente" que dominaba en aquellas librerías que contaban con establecimiento y cómo estos fondos respondían a su mercado. Los vericuetos de la investigación con bibliotecas privadas permiten relacionar una de las mejores evidencias que conocemos sobre la circulación de 
libros usados. Se trata de la obra de Vitrubio, De architectura, impresa en 1497 y adquirida en $1673^{4}$. Son 176 años de diferencia entre ambos eventos.

Este incunable perteneció a Carlos de Sigüenza y Góngora, y fue descrito con esa posesión por Jesús Yhmoff Cabrera en su catálogo desde I968 (I3I). A partir de tal fecha, se sabe que este libro en particular además contiene la obra de Sextus Julius Frontinus sobre los acueductos ${ }^{5}$, pero debió contener cuatro obras diferentes porque así fue impreso: Cleonides, Vitruvius, Frontinus y Politianus. La singularidad de este ejemplar, que se encuentra en México, es que además de mutilado de dos de sus partes posee un tercero en discordia, pues también hay otro incunable encuadernado: el de Julius Firmicus Maternus sobre la natividad ${ }^{6}$. Por otro lado, el Vitrubio también parece ser diferente en ciertos detalles, como las capitulares y las letras en espera. La comparación entre incunables queda pendiente porque lo que interesa destacar aquí es la escasa presencia de tan valiosos libros durante el periodo colonial. Al parecer, durante esa época no gozaron de tal estimación y no habría un coleccionismo patente.

Todos estos incunables a los que nos referimos fueron impresos en Venecia en la misma fecha, y suponemos que Sigüenza los adquirió juntos, porque su firma, tan característica, solo fue colocada en las primeras hojas del primero y el tercero, pero no del segundo. En efecto, desde los años ochenta se divulgó que los libros que pertenecieron a Sigüenza y que se conservan (Osorio 58) tienen esta singularidad: la firma del famoso novohispano. Un testimonio que también estamos estudiando, por dos razones. La primera, como evidencia de posesión, y la segunda, como testimonio de los precios de los libros en la época. En efecto, la singularidad de Sigüenza como poseedor de libros es que anotaba lo que suponemos es un año de compra y el costo que se pagó por el libro. En algunos casos, incluso apuntó la ruta comercial por la que le había llegado su ejemplar o el librero que le vendió un libro. En el caso de los incunables, Sigüenza pagó 2 pesos por el volumen. Más o menos lo que costaba en aquella época "un perro que guarda la tienda" (AGNM, RFI 48, f 234 v.) o "un tenedor de plata" (AGNM,

4 Marcus Vitruvius Pollio, De architectura libri X, Venetiis: per Simonem Papiensem dictum Bauilaquam, I 497. Biblioteca Nacional de México Inc. Clas. R.I. I 497-8-3-VIT.d.

5 Sextus Julius Frontinus, De aquaeductibus.... Venetiis: per Simonem Papiensem dictum Bauilaquam, 3 de agosto de 1497. Biblioteca Nacional de México RI 1497-8-3 VIT.d. https://data.cerl.org/istc/ icoo 742000 .

6 Julius Firmicus Maternus, De nativitatibus. Venice: Simon Bevilaqua, I3 June I497. Biblioteca Nacional de México Inc. Clas. R.I. I497-8-3-VIT.d. https://data.cerl.org/istc/ifoor90000. 
$I N, 78$, f. 36 r.), como evidencian algunos inventarios conservados de tiendas del periodo colonial, aunque sean solo estimaciones comparativas.

Ahora bien, considerando algunos de los libros registrados en una de las bibliotecas más famosas, la de Melchor Pérez de Soto, encontramos que este personaje también tenía libros que podríamos considerar usados (AGNM, I 440, ff. 92 r. y 92 v.). Por citar unos, el Libro de proprietatibus rerum en romance, de Bartholomaeus Anglicus, impreso en Toledo en I529, e Instrumentum primi mobilis, de Petrus Apianus (I495-I552), cuyo registro indica que el ejemplar estaba “sin lugar de impresión ni año". Lo anterior podría significar que solamente había perdido la portada y las tres primeras hojas, pues de la cuarta se tomó el título7. Dicha pérdida solemos explicarla por el uso y porque así se conservan numerosos libros antiguos en repositorios contemporáneos. De esta colección se preserva bastante información por el proceso inquisitorial del que fue objeto su dueño, y que terminó con su asesinato a manos de su compañero de celda en 1655 . Son I.5O2 ediciones registradas y medianamente identificadas desde I95I (Castanien I29-289), entre las que estaban Euclides, Copérnico, Erasmo, Kepler, Lull, Nostradamus, Paracelso, Tolomeo, Lope, Góngora, Cervantes sin el Quijote, y el Amadis, entre otros.

Los años de diferencia que hay entre las ediciones y la fecha del registro hacen suponer que se trató de la vigencia de una literatura determinada principalmente por los intereses de lectura de su época y región. Sin embargo, como podemos ver en este ejemplo, quienes registraron no indicaron que fuese usado. ¿Por qué? Es probable que en este caso tal consideración no fuese importante, pues a los inquisidores solo les interesaba determinar cuántas obras prohibidas estaban en esa biblioteca y no su rentabilidad. Como bien anotó Pedro Rueda:

[...] el libro no tiene por qué tener el mismo comportamiento que el resto de mercancías, ni, quizá, podamos estudiarlo al margen de los talleres de impresión, los negocios de librería y toda la base económica de precios y monedas que hacen rentable la economía del libro atlántico. ("La cultura” 73)

En efecto, la posibilidad de que existiera un comercio de libros usados estable, activo y aparentemente especializado en Nueva España es, por ahora, una opción de estudio viable que hemos iniciado porque hay evidencias para ello.

7 Se puede apreciar en la copia digitalizada de la obra Instrumentum primi mobilis (I534) de la Biblioteca Nazionale Centrale que se encuentra en Google Books. 


\section{Libros ¿viejos o usados?}

La idea de este tipo de mercado en la monarquía hispánica no es nueva, pues se ha considerado que fue "una forma de abastecimiento [que respondía] bien a estrategias comerciales para obtener la máxima rentabilidad” (Palmiste 599) de una mercancía como el libro. Su posibilidad permite también explicar ciertas obras presentes en las bibliotecas contemporáneas, que de otra manera resultan enigmáticas. Tal presencia es notoria en ciertas evidencias bibliográficas, consistente en aquellos libros que se conservan de personas que nunca estuvieron en el territorio novohispano, de lo que dan cuenta varios testimonios de procedencia, especialmente los ex libris, ex donos y anotaciones manuscritas. Una de estas evidencias es la nota de compra que dice: "En Sevilla en 8 días del mes de setiembre de 1667 compre este libro y costo sincuenta y cinco reales y medio que son 24 reales de plata y lo firme Licenciado don Juan Bonmaz y Navaz".

En efecto, existen otras ciudades con el nombre de Sevilla en América, pero por la fecha es probable que ese propietario sea un sevillano o un residente en Sevilla que compró un libro cinco años después de su impresión y del que no tenemos noticia en la Nueva España. Por la marca de fuego agustina de Puebla, presente en uno de sus cantos, sabemos que este libro estuvo después en el territorio novohispano. Lo contrario parece un poco complicado, aunque también tenemos noticia de que algunos conventos vendieron sus libros repetidos porque estas casas y otros poseedores así lo anotaron. Sin embargo, los casos que podemos documentar hasta ahora están fechados en el siglo xix. Tal práctica se explica por la existencia de bibliotecas privadas en el entorno del convento. Estas colecciones, siempre autorizadas, a la muerte del religioso se integraban a la biblioteca común. De ahí que en determinado momento algunas entidades religiosas tuviesen varios libros y ediciones repetidas.

Los testimonios que dan cuenta de la posesión personal en ciudades de la Península representan un universo de posibilidades que aún no hemos considerado en toda su dimensión, y que recientemente estamos abordando en colaboración con los catalogadores y responsables de fondos antiguos en México. Ellos son los más cercanos a los objetos que nos interesan, y en su trabajo cotidiano identifican mejor que cualquiera los testimonios en cuestión. Es el caso de los libros de

8 Anotación manuscrita en la guarda de la obra Andreoli, Giovanni Francesco, Controversiarvm forensivm in quibus variae iuris quaestiones excitatae acutissimè enucleantur, Venetiis: Bertanos, 1662. Biblioteca Nacional de México Rfo 94-43213. 
Antonio Álvarez de Abreu que ostentan su ex libris nobiliario9 y que se conservan en México. Álvarez de Abreu fue consejero de Indias y el primer marqués de la Regalía, además de autor de textos jurídicos y hermano de Domingo Pantaleón Álvarez de Abreu, quien desde 1743 estuvo a cargo de la diócesis de Puebla de los Ángeles y cuya biblioteca sí se ha estudiado (Lobo 4I7-438; Paz I-33).

No tenemos idea de cuántos son los objetos de esta procedencia en nuestro país. Hasta ahora hemos identificado uno en el Fondo Antiguo de la Biblioteca Central de la Universidad Nacional Autónoma de México y otro en la Biblioteca Eusebio Francisco Kino de la Compañía de Jesús en México. También hay trece reportados en el catálogo de la Biblioteca Nacional de México y otros repartidos en colecciones de la Universidad Nacional Autónoma de México. Todos estos están sin verificar. Por la nobleza e importancia del personaje, han sido identificados veintiún ejemplares en la Universidad Complutense de Madrid, cuatro en la Universidad de Salamanca y otros cuatro en la Universidad de Barcelona.

¿Cómo llegaron los libros de Álvarez de Abreu a estas tierras? Su hermano podría haberlos traído consigo en su comisión de Indias, aunque los estudios citados no mencionan nada al respecto. También es posible que llegaran por otros derroteros, como el comercio del libro usado, pues los "herederos se deshicieron de los libros legales y conservan todavía los más preciosos de aquella biblioteca” (Rodríguez 9I-I26) ${ }^{\mathrm{IO}}$. Ahora bien, existen otras evidencias que ayudan a observar cómo se movían estos libros "viejos" y son los testimonios que los libreros entregaron a la Inquisición. Por ejemplo, en la memoria de libros que presentó Juan de Rivera a la Inquisición en 1660 (O`Gorman 807-825) hay 253 ediciones antiguas entre las 706 registradas, incluidos cuatro incunables. Esto representa un $33 \%$ del fondo de su librería. Lo anterior también puede ser evidencia de cómo los diferentes agentes de libro tenían capacidad de adaptarse a su mercado y a las necesidades manifiestas de sus clientes.

Otro problema por resolver es determinar cómo vamos a caracterizar la información que recuperamos de los testimonios históricos, para establecer una distinción de aquello que entendemos en estos estudios como viejo y usado. Un ejemplo útil para explicar esto es la memoria del librero Domingo Sáenz de Pablo, fechada en I7I6. Ahí se registró un "Adrianus, Sextos pontifex.

9 Se puede ver en la página Antiguos Poseedores de la Biblioteca General Histórica en la Universidad de Salamanca, http://bibliotecageneralhistorica.usal.es/?q=persona/alvarez-de-abreu-antonio-jose. 
De sacramentis. Roma 1560" (AGNM, I, 763, ff. 404 r.-453 r.). Entre ambas fechas existen 156 años de diferencia. ¿¿Por este tiempo podemos considerar a este libro como viejo o como usado? Si se observa, es la misma cuestión del incunable de Sigüenza que hemos presentado aquí. A menos que podamos documentar una posesión anterior o diferentes posesiones, no es posible establecer categóricamente que un libro es usado. Es decir, cuando identificamos a un poseedor, como la monja que anotó en su libro "Soy del uso de María Manuela Septiem", y a otra que anotara después "Pasó a Sor Juana de Nuestra Señora de Guadalupe lo usa con licencia de su Prelada"II, estaríamos hablando de un libro usado.

Por su parte, ¿cómo entender que un libro es "viejo"? Es evidente que en la documentación sí existe una diferenciación respecto a estos libros, como ya hemos visto. Aquí hemos presentado casos que son muy notorios, y al menos tenemos certeza de que el incunable de Sigüenza tuvo una posesión anterior, pero no podemos saber exactamente por qué un libro era considerado viejo en aquella época. Incluso cuando se agrega "roto", "apolillado" o "bien tratado", solo se da cuenta de libros maltrechos. Por eso, hemos establecido como viejos los libros que son de siglos anteriores a los testimonios. En nuestro caso, todos los que son incunables o del siglo XVI al XVII, porque las evidencias estudiadas hasta ahora son en su mayoría del siglo XVIII. En este aspecto podemos permitirnos cierta ligereza, pues necesitamos hacer comparaciones entre los datos existentes en la documentación disponible o localizada para hacer estimaciones más cercanas. Sin embargo, parece evidente que un libro del que se reporta un cierto deterioro o maltrato, consecuente con el uso que evidencia su paso por muchas manos, sería un libro usado, en tanto que los otros podrían ser nuevos aunque tuviesen más de cincuenta años. Los intonsos son prueba de que algunos libros nunca encontraron un lector, pero de esta condición no contamos con noticia novohispana.

Otro aspecto que considerar son los diferentes precios que tenemos de una misma obra en el tiempo (Gómez 24-25), para contrastar con lo que se supone debería costar un libro en el mercado regular. Es decir, una vez que ha terminado su proceso de impresión, comienza el camino de circulación en el mundo de un libro. Es un tema más complejo, pero que debemos tener en cuenta para establecer si estos libros usados realmente representaron una oferta de libros

II Anotaciones manuscritas en tapa anterior y en verso de guarda anterior de la obra de Fernando Martagón (O. F. M.), Manual de exercicios espiritualespara practicar los santos desagravios de Christo señor nuestro, Impreso en México: en la Imprenta nueva Madrileña de D. Felipe de Zúñiga, y Ontiveros, calle de la Palma, 178r. Biblioteca Eusebio Francisco Kino 24162. 
más asequibles para diferentes personas. Esta temática recientemente ha cobrado interés para un grupo de investigadores europeos (Ammannati y Nuovo I-25). Dicho precio, entre 1558 y I762, estuvo bajo el arbitrio de la autoridad competente a través de la tasación y se encuentra en los libros impresos como "tasa". Se debe precisar que, en casi todos los casos, se establece un precio en maravedíes por pliego impreso ${ }^{\mathrm{I} 2}$, lo que constituía una política de precios controlados ejercida por la monarquía. Este era un requisito legal cumplido con poca frecuencia en los impresos novohispanos, lo que no significa que las obras dejaran de tasarse por una autoridad competente.

Lo referido en el párrafo anterior constituye otro problema para resolver: ¿Cómo determinar el precio de venta de los libros durante el periodo novohispano? Hasta donde sabemos, no contamos con esa información más que en ocasiones excepcionales, y de forma regular se trata de relaciones de libros procedentes de redes comerciales que informan el precio de un conjunto de libros y, algunas veces, de una sola pieza. Así, sabemos el precio de unos libros que llegaron en 1754: "2,, Alciati Emblemata cum Notis Minois $8^{\circ}$ a I2rs. OO3" (AGNM, IV, I29I, f. I v.). Ahora bien, ¿fue este el libro de venta fijo o habría otros factores involucrados? Sabemos que la tasa oficial era para libros en rama, por lo que no incluiría libros encuadernados (ya fuese en pergamino, piel o papel). Estas piezas implicarían la negociación de los precios por libreros y mercaderes con sus compradores. Los datos muestran que las encuadernaciones influían en la tasación de libros de difuntos. Así se aprecia en algunos testimonios donde se apunta "pergamino", "badana", "pasta" o "vitela”, entre otros. Tal información no necesariamente se encuentra en las tasaciones, sino también en las memorias elaboradas para el procedimiento inquisitorial de 1632.

Por otro lado, contamos con mayores evidencias de los precios de segunda mano que se establecieron y que obtenemos de almonedas, pleitos comerciales, inventarios y notas de los propios poseedores. Tal información requiere compilación y sistematización, pero además tiene un riesgo adicional. En efecto, solo con aquellas memorias que contienen datos de ciudades y años de impresión o en los casos en los que no hay duda de que se trata de cierta edición, podremos determinar con certeza cuál fue la edición registrada a la que se puso un precio.

12 Por ejemplo, los seis maravedíes por pliego, y en total 1.224 maravedíes en que deberían venderse los 204 pliegos, "sin principios ni tablas", que se emplearon en la obra de María de la Antigua (I56616I7), Desengaño de religiosos y de almas que tratan de virtud... En Seuilla: por Juan Cabeças, I678. Biblioteca Nacional de México 98-24396. 
En otros casos, es una mera suposición que resulta importante y que se contrasta con los datos que hemos obtenido. Estos resultados requieren explicar la circulación de una literatura que no consideraríamos contemporánea al testimonio histórico, excepto cuando se indique, lo que significa que, para acercarnos a esta problemática del valor de ideas y conocimientos con respecto a la antigüedad de los libros, solo podríamos hacerlo a partir de testimonios que registren con detalle las ediciones.

En los otros casos, en aquellas memorias que solo registran autores y títulos, la identificación de una edición concreta depende de la metodología de trabajo de cada investigador. En muchos casos, se determinó que los libros poseídos por una persona son contemporáneos a la fecha en que se elaboró el documento de estudio. Nuestra evidencia indica que no siempre fue así y no debemos obviar esos datos. Es más, se afirma que fueron leídos. La lectura es un tema muy arenoso de trabajar, pues requiere evidencias muy puntuales. Huellas que no son escasas, pero en su mayoría son anónimas y representan otro camino de investigación, diferente al que aquí exponemos.

\section{Consideraciones finales}

Como se ha apreciado, la temática del libro usado es mucho más compleja de lo que parece. La tarea de identificación no es ardua solamente por la cantidad de libros que se requiere revisar para localizar testimonios fiables. Debemos asimismo registrar y comparar todas esas valoraciones que podrían darnos una idea de que se trata de libros usados por el deterioro que presentaban, en memorias de poseedores y libreros primordialmente, sin descartar otras fuentes que resultarían interesantes. En este tenor, determinar que un libro es solamente viejo resulta mucho más complicado por lo que hemos expuesto. Además, debemos preguntarnos sobre la rentabilidad que tendría para los libreros contar con una oferta de libros superior a los cien años. Al parecer, tener disponibilidad de esas ediciones fue una decisión de mercado. También debemos considerar la vida de cada librero, pues solo en casos de redes familiares podemos explicar la transmisión de las ediciones en un mismo negocio. En el caso de los aventureros, ¿por qué comprarían ediciones tan antiguas para sus librerías?

Para esta temática quizá también sea necesario abandonar del todo la idea tan arraigada de lo costosos que eran los libros en la América española, especialmente porque esta afirmación, con pocos datos de soporte, ha sido determinante 
para concluir que por ese "costo excesivo" el acceso a los libros solo fue posible para un grupo muy reducido de personas. En concreto, quienes tenían posibilidad económica para ello. No dudamos en absoluto de que muchos libros sí resultasen caros. Contamos con algunas evidencias históricas para afirmarlo, pero en estos casos se trata de personas muy interesadas en la adquisición de los libros. ¿De qué otra manera explicamos los 8 pesos que pagó por su libro don Pedro de Cervantes Velásquez de la Cadena ${ }^{13}$ ? Además, no tenemos certeza de que ese alto costo esté determinado por la obra misma o se relacione con una posesión que distinguir. Desde luego, la encuadernación en pergamino que tiene este texto no hace suponer que haya sido una característica que elevase el costo. En estos casos, aparentemente tendremos que movernos con mesura y analizar con detalle cada objeto valuado para interpretar mejor las evidencias.

Por otro lado, la circulación de ediciones antiguas, y en un porcentaje tan amplio como las evidencias están demostrando, tanto en el comercio libresco como en el hogar novohispano, da cuenta de un mercado que se sostiene por intereses comerciales. En suma, hay oferta porque hay una demanda. De ahí que resulte tan sugestivo acercarnos en determinado momento a quienes movían estos fondos librarios. Hoy sabemos que algunos libreros vendían mercancía nueva y vieja porque lo reportan en sus propias memorias, como Bartolomé de Mata, el primer librero localizado que declaró vender y comprar libros usados (AGNM, I, 363, ff. 304 r.-305 r.). Ciertamente, es necesario reconstruir las redes comerciales de los libreros que participaron en el mercado del libro usado para comprender la relación que tal comercio tuvo entre inquisidores y lectores. No olvidemos que fue el Santo Oficio el que promovió la elaboración de ambas fuentes primarias, las cuales permiten acercarse a estos saberes compartidos entre generaciones.

A este entramado y sus intereses dedicamos esta reflexión, porque queremos comprender si todos los libreros participaron en este comercio y si alguno de ellos puede considerarse especializado en la venta de segunda mano. Esto porque los estudios realizados sobre libreros en la Edad Moderna han demostrado que se trata de un comercio basado en estructuras familiares, que fueron a su vez eslabones de redes comerciales formadas en Europa ya desde el siglo XV. En efecto, la documentación localizada igualmente permitió identificar

13 Jaime de Corella, Practica de el confessonario, y explicación de las LXV proposiciones condenadas por la santidad de No.S.P. Inocencia XI, Madrid: Matheo de Llanos, 1690 Biblioteca Nacional de México 66-I278I. 
protagonistas que creemos se especializaron en libro usados. Nos referimos a los Cueto (Joaquín, Manuel, Miguel y José) y a los Quinto (Antonio y Joseph). ¿Cómo podemos determinarlo? En principio, porque no encontramos que hayan tenido una participación muy relevante en las redes comerciales de abastecimiento que llegaban de Europa. Puede compararse, por ejemplo, la participación en dicho comercio de Manuel de Cueto con la de Felipe Zúñiga y Ontiveros (Suárez 23I-232).

Los personajes mencionados, a diferencia de otros, estuvieron presentes en el registro y tasación de bibliotecas de difuntos, lo que podría demostrar que, en su fondo de librería, tendrían más material usado que nuevo y se contrastaría con lo anotado por Moreno respecto a otros libreros decimonónicos (Moreno, "Hacia" I45). De ahí el estudio que actualmente realizamos sobre Joseph de Quinto, quien aparentemente fue hijo de Antonio del mismo apellido. De estos libreros, activos en la capital novohispana entre 1732 y I780, sabemos muy poco. Es más, casi nada. Ambos aparecen haciendo el trámite inquisitorial para los difuntos establecido en I632, que ya mencionamos, con catorce trámites documentados. Por ello, consideramos que estos libros fueron su fuente principal de abastecimiento de mercancía y, gracias a otra información localizada de I770, sabemos que el Santo Oficio había concedido a Joseph "licencia y facultad para corregir" libros en circulación (AGNM, I, 825, f. I67 r.).

Ya habíamos tenido noticia de Joseph de Quinto por su relación con otro librero, Felipe Pérez del Campo, al que hemos mencionado (García y Montiel 9o). Los Quinto también podrían estar relacionados con la familia de Juan Justo de Vera, un mercader sevillano con varios viajes trasatlánticos entre 1732 y 1768. Sabemos que su hijo Manuel abasteció de libros a los mercaderes novohispanos con casi 76 cajones durante todo su periodo de actividad ${ }^{14}$. Esta podría ser otra fuente de aprovisionamiento de la librería de Quinto, que contaba con 2.132 ediciones. Sin embargo, todavía no hemos encontrado testimonios que apunten hacia este giro comercial, uno que mostrase a los Quinto participando de la venta regular de libros nuevos que llegaban desde Europa. Por su parte, los difuntos aportarían a cualquier librero una oferta variada y llamativa para las personas interesadas. De Joseph Quinto se conserva una memoria que entregó a la Inquisición en 1759 (AGNM, I, 992, ff. 75 r.-I20 v.) y la noticia de que entregó una más en 1780 , que no se conserva. En la memoria que podemos analizar,

I En el Archivo General de la Nación de México se conservan numerosos trámites relacionados con esos cajones de libros. 
ordenada por estantes y folios, algunos libros podrían ser usados como la edición veneciana del Petrarcha espiritual de Girolamo Malipiero, de la que se imprimieron varias ediciones, pero todas en el siglo XVI. Ahora bien, ¿sería rentable tener en oferta un libro "viejo"?

Sin duda, este material representa un enorme caudal de información que podremos cruzar con datos ya compilados. Lo que efectivamente demuestran las evidencias aquí presentadas y otras que hemos compilado es que hubo libros usados durante el periodo novohispano. Estamos seguros de que los resultados ayudarán a determinar si en efecto el fondo de librería de Quinto estuvo conformado en gran parte por libros usados o, por el contrario, fue una tienda que ofertaba novedades. El estudio del comercio de libros, en sus múltiples formas, ayuda a comprender mejor la cultura de los libros en Nueva España y, por tanto, a valorar el legado bibliográfico que todavía conservamos. Si bien las evidencias no son del todo concluyentes, al menos confirman la circulación de algunos libros usados que llegaron desde la Carrera de Indias a este territorio a partir del siglo XVi y la constante circulación de saberes entre generaciones. Por eso, con los testimonios compilados hasta ahora (que deberemos seguir aumentando) podemos comenzar a delinear unas geografías culturales que permitan integrar la circulación de estos libros en la cultura escrita de la época, y quizá en cierta medida determinar su impacto social.

\section{. \\ $\begin{array}{llllllllllll} & \text { I } & B & L & I & O & G & R & A & \text { I } & A\end{array}$}

\section{F U E N T ES P R I MARIA S}

\section{A. Archivos}

Archivo General de la Nación, Ciudad de México, México (AgNM).

Edictos (E) I, exp. I (23 de octubre de 1613).

Inquisición (I) 363 , exp. 35 (1629).

440 , exp. I (1665).

763 , exp. 3 (1716).

825, exp. 3 (1768-1770).

986, exp. 9 (1756). 
992 , exp. 6 (1759).

IIO०, exp. 6.

I217, exp. 13 (1785).

I296, exp. 4 (1786).

1333, exp. I8 (1776).

I40I, exp. I6 (178I).

Indiferente Virreinal (IV), caja 30, exp. 2 (9 de septiembre de 1770).

Caja I291, exp. 4 (1753-1754).

Caja 4217, exp. 42 (1612).

Caja 5811, exp. 56 (1609).

Caja 4965, exp. 23 (1760).

Jesuitas (JS), volumen III - 26, exp. 2 (1603).

26, exp. 27 (1616).

Intestados (IN) 78, exp. I (I780-I783).

Real Fisco de la Inquisición (RFI) 48, exp. I2 (I69I).

Archivo Histórico Nacional, Madrid, España (AHN).

Jesuitas (JS), leg. 91, n. ${ }^{\text {os }}$ 67-77.

\section{B. Impresos}

Index librorum prohibitorum et expurgatorum, ed. Bernardo Salvador y Rojas. Madrid: apud Ludouicum Sanchez Typhograpum, 16r2.

Recopilación de Leyes de los Reinos de las Indias. Madrid: Julián Paredes, I68I.

\section{FUENTESSECUNDARIAS}

Ammannati, Francesco y Angela Nuovo. "Investigating Book Prices in Early Modern Europe: Questions and Sources". JLIS, vol. 8, n. ${ }^{\circ}$, 2017, pp. I-25.

Castanien, Donald G. "A Seventeenth Century Mexican Library and the Inquisition”. Tesis de Doctorado en Filosofía, University of Michigan, I95I.

Castañeda, Carmen. "Libros como mercancías y objetos culturales en la feria de San Juan de los Lagos, México, I804”. Estudios del Hombre, n. ${ }^{\circ}$ 20, 2005 , pp. 87-II6.

---. "Libros en la Nueva Vizcaya”. Historias, n. 31 , 1993-1994, pp. I27-I33.

Fernández del Castillo, Francisco. Libros y libreros del siglo XVI. Ciudad de México: Tipografía Herrero Hermanos, i9i 4. 
García, Idalia. "El movimiento de los libros en la Nueva España: consideraciones sobre las fuentes inquisitoriales". Antrópica, Revista de Ciencias Sociales y Humanidades, vol. 2, n. ${ }^{\circ}$, 2016, pp. 57-71.

---. La vida privada de las bibliotecas: rastros de colecciones novohispanas, I700-I80o. Universidad del Rosario y Universidad Autónoma Metropolitana, 2019. En prensa.

García, Idalia y Ana Cecilia Montiel. "Una vida entre cajones de libros: Felipe Pérez del Campo en la Nueva España”. Estudios de Historia Novohispana, n. ${ }^{\circ}$ 43, 2010, pp. 5I-I07, https://doi.org/10.22201/iih.24486922e.2010.043.23470.

García Cárcel, Ricardo. Veinte años de historiografía de la Inquisición. Algunas reflexiones. Valencia: Real Sociedad Económica de Amigos del País, 1996.

García Morales, Justo. “Un informe de Campomanes sobre las bibliotecas españolas” [incluye transcripción de "Noticia abreviada de las bibliotecas y monetarios de España (informe firmado en Madrid el 25 de marzo de 1788 )" de Pedro Rodríguez Campomanes]. Revista de Archivos, Bibliotecas y Museos, n. ${ }^{\circ}$ 75, 1968-1972, pp. 91-I26.

Gómez Álvarez, Cristina. "Notas para el estudio de la circulación del libro usado en la Nueva España, 1750-1819”. Insurgencia y republicanismo, coordinado por J. Raúl Navarro García. Madrid: CSIC, 2006, pp. II-25.

González y González, Enrique y Víctor Gutiérrez Rodríguez. "Libros en venta en el México de Sor Juana y Sigüenza, 1655-1660”. Del autor al lector: libros y libreros en la historia, coordinado por Carmen Castañeda. Ciudad de México: Miguel Ángel Porrúa; Conacyt; Ciesas, 2002, pp. I03-132.

González Sánchez, Carlos Alberto y Pedro Rueda Ramírez. “'Con recato y sin estruendo’: puertos atlánticos y visita inquisitorial de navíos”. Annali della Scuola Normale Superiore di Pisa. Classe di Lettere e Filosofia, vol. 5, n. ${ }^{\circ}$ I-2, 2009, pp. 473-506.

Hampe Martínez, Teodoro. Bibliotecas privadas en el mundo colonial. Frankfurt am Main; Madrid: Vervuert; Iberoamericana, 1996.

Leonard, Irving A. "On the Mexican Book Trade, 1576 ". Hispanic Review, vol. I7, n. ${ }^{\circ}$ I, 1949 , pp. I8-34. DOI: https://doi.org/I0.2307/471082.

---. "On the Mexican Book Trade, 1683". The Hispanic American Historical Review, vol. 27, n. ${ }^{\circ}$ 3, 1947, pp. 403-435, DOI: https://doi.org/10.2307/2507916.

Leonard, Irving y Otis H. Green. "On the Book-Trade in Mexico City, I60o. A Chapter in Cultural History”. Hispanic Review, n. ${ }^{\circ}$ IX, I940, pp. I-40.

Lobo Cabrera, Manuel. "La biblioteca de Domingo Pantaleón Álvarez de Abreu, arzobispo de Santo Domingo". Anuario de Estudios Atlánticos, vol. I, n. ${ }^{\circ} 35$, 1989, pp. 417-438. 
Medina, José Toribio. Historia del Tribunal del Santo Oficio de la Inquisición en México. Santiago de Chile: Imprenta Elzeviriana, I905.

Moreno Gamboa, Olivia. "Hacia una tipología de libreros de la ciudad de México (1700-1778)". Estudios de Historia Novohispana, n. ${ }^{\circ}$ 40, 2009 , pp. I2I-1 46, https://doi.org/10.2220I/ iih.24486922e.2009.040.15319.

---. La librería de Luis Mariano de Ibarra: Ciudad de México, 1730-I750. Ciudad de México: Ediciones de Educación y Cultura, 2009.

O’Gorman, Edmundo. “Bibliotecas y librerías coloniales, 1585-1694”. Boletín del Archivo General de la Nación, vol. 10, n. 4 , 1939, pp. 663-1006.

Osorio Romero, Ignacio. Historia de las bibliotecas novohispanas. Ciudad de México: SEP; Dirección General de Bibliotecas, 1986.

Palmiste, Clara. "La compra de libros 'usados' y de bibliotecas privadas en algunas librerías sevillanas. Finales del siglo XVII, principios del siglo XVIII". La memoria de los libros: estudios sobre la historia del escrito y de la lectura en Europa y América, t. 2, dirigido por Pedro M. Cátedra y María Luisa López Vidriero. Salamanca: Instituto de Historia del Libro y de la Lectura, 2004, pp. 599-609.

Paz Sánchez Manuel de. "Vísperas de un nuevo mundo: biblioteca y testamento inédito del arzobispo Domingo Pantaleón Álvarez de Abreu (1683-1763)”.Naveg@mérica (revista electrónica editada por la Asociación Española de Americanistas), n. ${ }^{\circ}$ I6, 2016.

Pinto Crespo, Virgilio. Inquisición y control ideológico en la España del siglo XVI. Madrid: Taurus, 1983 .

Rojo Vega, Anastasio. "Los grandes libreros españoles y América”. Cuadernos Hispanoamericanos, n. ${ }^{\circ}$ 500, I992, pp. II5-I32.

Rueda Ramírez, Pedro. "La cultura escrita en el mundo atlántico colonial: claves historiográficas, retos y perspectivas". Erebea. Revista de Humanidades y Ciencias Sociales, n. ${ }^{\circ}$ 2, 2012 , pp. 53-76.

---. “Los libreros Juan López Román y Antonio de Toro en la Carrera de Indias”. El libro en circulación en el mundo moderno en España y Latinoamérica, dirigido por Pedro Rueda Ramírez. Madrid: Calambur, 2012, pp. 45-75.

---. "Libreros y librerías poblanas: la oferta cultural en el mundo moderno". Miradas a la cultura del libro en Puebla: bibliotecas, tipógrafos, grabadores, libreros y ediciones en la época colonial, editado por Marina Garone Gravier. Ciudad de México: Ediciones de Educación y Cultura; UNAM; Instituto de Investigaciones Bibliográficas, 2012, pp. 377-400.

---. Negocio e intercambio cultural: el comercio de libros con América en la Carrera de Indias, siglo XVII. Sevilla: Universidad, Diputación, CsIC, 2005. 
Schons, Dorothy. Book Censorship in New Spain. Ann Arbor: Edwards, 1949.

Suárez Rivera, Manuel. "El negocio del libro en Nueva España: los Zúñiga Ontiveros y su emporio tipográfico, 1756-1825”. Tesis de Doctorado en Historia, Universidad Nacional Autónoma de México, 2013.

Tomás Pardo, José. Ciencia y censura: la Inquisición española y los libros cientificos en los siglos XVI y XVIII. Madrid: CSIC, I99I.

Torre Revello, José. El libro, la imprenta y el periodismo en América durante la dominación española. Ciudad de México: UnAM, I991.

Vega, María José. "Notas teológicas y censura de libros en los siglos XVI y XVII”. Las razones del censor. Control ideológico y censura de libros en la primera Edad Moderna, editado por Cesc Esteve. Barcelona: Studia Aurea Monografica, Universitat Autònoma de Barcelona, 2013, pp. 25-54.

Wilkinson, Alexander S. "Lost Books Printed in French before 1601 ". The Library, vol. ı, n. 2 2, 2009, pp. 188-205.

Yhmoff Cabrera, Jesús. Catálogo de incunables de la Biblioteca Nacional de México, 2. ${ }^{a}$ ed. Ciudad de México: UnAM, 1987.

Zahar Vergara, Juana. Historia de las librerias de la Ciudad de México: evocación y presencia, $3 .{ }^{a}$ ed. Ciudad de México: Unam, Centro Universitario de Investigaciones Bibliotecológicas, 2006. 